\title{
COVID-19 Pandemic and Physical Theray Rehabilitation: A Short Review
}

\author{
Hafsa Gul Khattak ${ }^{1}$ and Mir Arif Hussain ${ }^{2 *}$ \\ ${ }^{1}$ Lecturer Physical Therapy, Department of Physical Therapy, University of Lahore, Islamabad \\ ${ }^{2}$ Assistant Professor Physical Therapy, Department of Rehabilitation Sciences, Shifa Tameer-e-Millat University, Islamabad
}

*Corresponding author: Mir Arif Hussain, Assistant Professor Physical Therapy, Department of Rehabilitation Sciences, Shifa

Tameer-e-Millat University, Islamabad

\begin{tabular}{|c|c|}
\hline ARTICLE INFO & ABSTRACT \\
\hline Received: 慧 December 15, 2020 & $\begin{array}{l}\text { Citation: Hafsa Gul Khattak, Mir Arif Hussain. COVID-19 Pandemic and Physical Theray } \\
\text { Rehabilitation: A Short Review. Biomed J Sci \& Tech Res 32(4)-2020. BJSTR. MS.ID.005297. }\end{array}$ \\
\hline 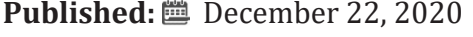 & \\
\hline
\end{tabular}

\section{Mini Review}

Corona virus (CoV) was first discovered in 1960 among adults and children suffering from respiratory infection. It is termed severe acute respiratory distress syndrome (SARS) as it affects upper and lower respiratory tract [1]. The first case of corona was reported in Wuhan city of China at the start of December 2019 [2]. It was initially presented as pneumonia in several person without any known cause, however some report showed that people suffering from this disease had a contact history in local Chinese seafood market [3]. CDC identified the novel corona virus by taking swab sample from throat of affected patient, which was named as Covid-19 by WHO [4]. The patients affected with corona virus present with a variety of symptoms from no or mild symptoms to severe breathing difficulty or even in worse conditions leading to organ damage including renal and cardiac failure. Pyrexia, malaise, productive cough, difficulty breathing, muscle weakness, and headache are some of the common symptoms. Other less common symptoms included runny nose, diarrhea, and blood during cough, chest pain, and nausea [5]. The virus spreads when a healthy individual inhales infected particles released through respiratory secretions of an affected person, which travels within a range of $2 \mathrm{~m}$ from infected person. SARS-CoV stays active on hard surfaces for twenty four hours while on soft surfaces it remains for eight hours. The infected particles released through cough and sneeze remain active for less than three hours in air [6].

During Covid-19 pandemic it is a difficult task to manage huge number of infected patients while simultaneously dealing with noninfectious patients suffering from other medical problem [7]. A major concern during pandemic is increased patient load on emergency departments. In an emerging collaborative model of care, physical therapists assists emergency department physicians in diagnosis and treatment of neuromusculoskeletal and ambulatory disorders e.g., occurrence of fall in elderly persons, vertigo, low back pain etc. [8] Physical therapists working in emergency departments reduces inpatient admissions for musculoskeletal injuries and also decrease overcrowding of persons during pandemic reducing burden in emergency departments [8]. Globally, Physiotherapy is a well-known profession and physiotherapists play a key role in wellbeing of patients admitted in hospital with confirmed or suspected cases of Covid-19 [9]. Physiotherapists performs rehabilitation and respiratory management of Corona affected patients. Productive cough is an uncommon symptom reported in Covid-19 patients [10] however, patients who has other diseases like cystic fibrosis, neurological diseases have in-effective cough and face difficulty in clearing copious respiratory secretion [11]. Covid-19 patients associated with respiratory failure have insufficient airway clearance. Physiotherapist may help in positioning of ventilated patients for air clearance and optimization of oxygen supply by adopting prone position for patients [12]. The risk for ICU acquired muscular weakness is greater in Covid-19 patients who are admitted in ICU for prolong intensive treatment at hospital, which limit their mobility and increase risk for mortality among Covid-19 patients [13,14]. Physiotherapy rehabilitation is necessary to start promptly in Covid-19 patients to decrease risks for ICU acquired weakness and to add functional return 
to home in surviving patients of Covid-19 [9]. Post-intensive care syndrome (PIC) is likely to occur in Covid-19 patients after critical illness resulting in physical impairments, decrease lung functions, cognitive impairments, depression decreased muscle strength affecting ability to perform ADLS and IADLS [15]. After early examination and screening done by physiotherapist, these impairments can be managed properly [16].

It is advantageous to provide conventional oxygen therapy via facemask in respiratory distress patients (target SpO2 > 94 $\%)$. It also suggested to use face mask to avoid dispersal of virus contaminants [17]. The risk of contamination and transmission of viral droplets are greater in nasal cannula that is why not recommended in Covid-19 patients [18]. High flow nasal oxygen are preferable with a $60 \%$ of flow rate. Surgical mask should be properly place on patient mouth and nose as used in conventional oxygen therapy and should be changed after six or eight hours of use [19]. If one hour of non-invasive ventilation / continuous positive airway pressure shows no improvement, then medical team should be informed and treatment should be shifted to invasive ventilator technique. It is necessary to perform all procedures with prevention and control measures taken properly [20]. Regular change in position is recommended in mechanical ventilated Covid-19 patients to improve ventilation and for prevention of bed sores. Semi-prone and prone positions are recognized for better gaseous exchange and improving lung functions in Covid-19 patients. To minimize muscle work while maintaining stable position, use of pillow or cushion is recommended [21]. Nebulizers and humidifiers are not recommended in Covid-19 patients due to increased risk for disease transmission. However, if it is required can be used with proper precautions to prevent aerial dispersion of viral droplets by use of antiviral filters in nebulizers [22]. A decrease in lung compliance is observed in acute Covid-19 and respiratory failure patients with an increased work of breathing [23]. Therefore certain physical therapy interventions should not be practiced in acute Covid-19 patients as these may increase load on respiratory muscle and increase work of breathing i.e., pursed lip breathing, cleaning of nasal pathways, exercise training, spirometer, manual mobilizations, mobility during acute instability [18] Physiotherapist play a vital role in rehabilitation of Covid-19 patients. The duration in hospital stay can be minimized and return to functional activities can be achieved by early mobilizing the patient (Passive and active ROM, bed mobility, sitting balance, sit to stand transitions, standing, tilt table) [24].

\section{References}

1. Malik YS, Sircar S, Bhat S, Sharun K, Dhama K, et al. (2020) Emerging novel coronavirus (2019-nCoV)-current scenario, evolutionary perspective based on genome analysis and recent developments. Veterinary quarterly 40(1): 68-76.
2. (2020) Organization WH. Novel coronavirus (2019-nCoV). Situation report p. 28.

3. Chen N, Zhou M, Dong X, Qu J, Gong F, et al. (2020) Epidemiological and clinical characteristics of 99 cases of 2019 novel coronavirus pneumonia in Wuhan, China: a descriptive study. The Lancet 395(10223): 507-513.

4. Huang C, Wang Y, Li X, Ren L, Zhao J, et al. (2020) Clinical features of patients infected with 2019 novel coronavirus in Wuhan, China. The lancet 395(10223): 497-506.

5. Xu XW, Wu XX, Jiang XG, Xu KJ, Ying LJ, et al. (2020) Clinical findings in a group of patients infected with the 2019 novel coronavirus (SARSCov-2) outside of Wuhan, China: retrospective case series. bmj pp. 368.

6. Van Doremalen N, Bushmaker T, Morris DH, Holbrook MG, Gamble A, et al. (2020) Aerosol and surface stability of SARS-CoV-2 as compared with SARS-CoV-1. New England Journal of Medicine 382(16): 1564-1567.

7. Ranney ML, Griffeth V, Jha AK (2020) Critical supply shortages-the need for ventilators and personal protective equipment during the Covid-19 pandemic. New England Journal of Medicine 382(18): e41.

8. Kim HS, Strickland KJ, Mullen KA, Lebec MT (2018) Physical therapy in the emergency department: A new opportunity for collaborative care. The American journal of emergency medicine 36(8): 1492-1496.

9. Thomas P, Baldwin C, Bissett B, Boden I, Gosselink R, et al. (2020) Physiotherapy management for COVID-19 in the acute hospital setting: clinical practice recommendations. Journal of Physiotherapy 66(2): 7382.

10. Guan WJ, Ni ZY, Hu Y, Liang W, Ou CQ, et al. (2020) Clinical characteristics of coronavirus disease 2019 in China. New England journal of medicine 382(18): 1708-1720.

11. Thomas P, Baldwin C, Bissett B, Boden I, Gosselink R, et al. (2020) Physiotherapy management for COVID-19 in the acute hospital setting: Recommendations to guide clinical practice. Pneumon 33(1).

12. (2020) ANZICS COVID-19 Guidelines.

13. Kress JP, Hall JB (2014) ICU-acquired weakness and recovery from critical illness. New England Journal of Medicine 370(17): 1626-1635.

14. Herridge MS, Tansey CM, Matté A, Tomlinson G, Diaz-Granados N, et al. (2011) Functional disability 5 years after acute respiratory distress syndrome. New England Journal of Medicine 364(14): 1293-1304.

15. Ohtake PJ, Lee AC, Scott JC, Hinman RS, Ali NA, et al. (2018) Physical Impairments Associated With Post-Intensive Care Syndrome: Systematic Review Based on the World Health Organization's International Classification of Functioning, Disability and Health Framework. Physical therapy 98(8): 631-645.

16. Fan E, Dowdy DW, Colantuoni E, Mendez-Tellez PA, Sevransky JE, et al. (2014) Physical complications in acute lung injury survivors: a 2-year longitudinal prospective study. Critical care medicine 42(4): 849-859.

17. (2020) Organization WH. Clinical management of severe acute respiratory infection (SARI) when COVID-19 disease is suspected: interim guidance, 13 March 2020. World Health Organization.

18. Lazzeri M, Lanza A, Bellini R, Bellofiore A, Cecchetto S, et al. (2020) Respiratory physiotherapy in patients with COVID-19 infection in acute setting: a Position Paper of the Italian Association of Respiratory Physiotherapists (ARIR). Monaldi Archives for Chest Disease 90(1).

19. Hui DS, Chow BK, Lo T, Tsang OT, Ko FW, et al. (2019) Exhaled air dispersion during high-flow nasal cannula therapy versus CPAP via different masks. European Respiratory Journal 53(4): 1802339.

20. (2020) Delle Infezioni IC. Indicazioni Per La Fisioterapia Respiratoria In Pazienti Con Infezione Da COVID-191. 
21. Ding L, Wang L, Ma W, He H (2020) Efficacy and safety of early prone positioning combined with HFNC or NIV in moderate to severe ARDS: a multi-center prospective cohort study. Critical care 24(1): 28.

22. Thomas P, Baldwin C, Bissett B, Boden I, Gosselink R, et al. (2020) Physiotherapy management for COVID-19 in the acute. JAMA 323(11) 1039-1040.

\section{ISSN: 2574-1241}

DOI: 10.26717/BJSTR.2020.32.005297

Mir Arif Hussain. Biomed J Sci \& Tech Res

(c) (P) This work is licensed under Creative

Submission Link: https://biomedres.us/submit-manuscript.php
23. Wujtewicz M, Dylczyk Sommer A, Aszkiełowicz A, Zdanowski S, Piwowarczyk S, et al. (2020) COVID-19-what should anaethesiologists and intensivists know about it? Anaesthesiology intensive therapy 52(1): 34-41.

24. Respiratory Management of COVID 192020.

\begin{tabular}{ll} 
BIOMEDICAL & Assets of Publishing with us \\
RESEARCHES & - Global archiving of articles \\
\hline ISSN: $2574-1241$ & Immediate, unrestricted online access \\
& - Rigorous Peer Review Process \\
&
\end{tabular}

